\title{
Layered Clay/Epoxy Nanocomposites: Thermomechanical, Flame Retardancy, and Optical Properties
}

\author{
Elcin Kaya, ${ }^{1}$ Metin Tanoğlu, ${ }^{1}$ Salih Okur $^{2}$ \\ ${ }^{1}$ Department of Mechanical Engineering, İzmir Institute of Technology, Gülbahçe Campus, 35437 Urla, İzmir, Turkey \\ ${ }^{2}$ Department of Physics, Gülbahçe Campus, 35437 Urla, Izmir, Turkey
}

Received 7 February 2007; accepted 4 October 2007

DOI 10.1002/app.28168

Published online 10 April 2008 in Wiley InterScience (www.interscience.wiley.com).

\begin{abstract}
In this study, layered clay/polymer nanocomposites were developed based on epoxy resins and montmorillonite as the nanoplatelet reinforcement. Clay particles were treated with hexadecyltrimethylammonium chloride (HTCA) through an ion exchange reaction. In this way, $\mathrm{Na}^{+}$interlayer cations of the clay is exchanged with onium cation of the surfactant that turns the hydrophilic clays (MMT) to organophilic (OMMT) characteristics. Thermal analysis results revealed that the glass transition
\end{abstract}

temperature $\left(T_{g}\right)$ and the dynamic mechanical properties including the storage and loss modulus of the neat epoxy resin increases by the incorporation of clay particles. It was also found that flame resistance of the polymer is improved by the addition of the clay particles. (c) 2008 Wiley Periodicals, Inc. J Appl Polym Sci 109: 834-840, 2008

Key words: nanocomposites; layered clay; polymer; optical transmission; dynamic mechanical analysis

\section{INTRODUCTION}

Nanocomposites have been recently used in diverse applications ranging from high barrier packaging for food and electronics ${ }^{1}$ to automotive and aerospace applications. ${ }^{2}$ They display rather unique properties even at relatively lower filler content, by comparison with more conventional particulate-filled polymers. Their improved mechanical and thermal properties, gas permeability resistance, and fire retardancy is related to the microstructure achieved in processing these materials.

The layered clays have structural units having two tetrahedral sheets and one edge-shared octahedral sheet of aluminum or magnesium hydroxide between the two. Between these layers, galleries that bonds the layers by Van der Waals forces exists. Isomorphic substitution of $\mathrm{Al}^{+3}$ with $\mathrm{Mg}^{+2}, \mathrm{Fe}^{+2}$, or $\mathrm{Mg}^{+2}$ with $\mathrm{Li}^{+1}$, or $\mathrm{Si}^{+4}$ with $\mathrm{Al}^{+3}$ generates negative charges balanced with the gallery cations of $\mathrm{Na}^{+}, \mathrm{Ca}^{+2}$. The cations in the clay galleries give hydrophilic characteristic to the natural clays, which is a drawback to homogeneously disperse them in organic polymers. It has been demonstrated that this can be overcame by the suitable surface modification

\footnotetext{
Correspondence to: M. Tanoğlu (metintanoglu@iyte.edu.tr).

Contract grant sponsor: The Scientific and Technical Research Council of Turkey (TÜBITAK-MAG); contract grant number: 104M365 project.
}

Journal of Applied Polymer Science, Vol. 109, 834-840 (2008) C 2008 Wiley Periodicals, Inc. of clays. ${ }^{3,4}$ The cations in the clay galleries may be exchanged with the alkyl ammonium cations through an ion exchange reaction. So, the modified clay becomes organophilic having a lower surface energy and good interactions with the organic polymer. $^{5}$

Depending on the nature of the layered clay and polymer matrix, and the level of interfacial interactions between them, various types of morphology; phase separated, intercalated, or exfoliated nanocomposites can be obtained. While the clay particles form separated phases in phase separated structures, in intercalated nanocomposite polymer molecules penetrates into the galleries of the clay and interlayer spacing is increased. Exfoliated nanocomposites are obtained when the clay layers are completely delaminated and homogenously dispersed within the polymer matrix..$^{8-10}$ Because of homogenous distribution of the layers in the polymer matrix, exfoliated nanocomposites exhibits superior properties as compared with other structures. However, a strong electrostatic attraction between the clay layers and the gallery cations make it difficult to achieve complete exfoliation of layers in a polymer matrix. ${ }^{1}$ In general, three different approaches; melt intercalation, ${ }^{11}$ solution method, ${ }^{12}$ and in situ polymerization ${ }^{6}$ have been utilized to synthesize polymer/clay nanocomposites. In melt intercalation method, thermoplastic polymers are mechanically mixed with organophilic clay to exfoliate the clay layers in the polymer, while the clay and the polymer are dissolved in an organic solvent in the solution method. In in situ polymeriza- 
tion, organoclay is swollen in the thermosetting resins and exfoliation of the clay is expected during the polymerization. ${ }^{9}$

In our previous study, ${ }^{13}$ layered clay/epoxy nanocomposites were prepared by using pristine (MMT) and organically modified montmorillonite clay (OMMT) and epoxy resins via in situ polymerization and the effects of clay concentration on morphology and mechanical properties of the nanocomposites were investigated. Clay particles were treated with hexadecyltrimethylammonium chloride (HTAC). The X-ray diffraction (XRD) technique results showed that d-spacing expanded from $14.3 \AA$ to $18.1 \AA$, after modification of the clays. It was also found that nanocomposites with OMMT exhibited better dispersion than montmorillonite (MMT) and the addition of the clay particles affects the mechanical properties up to some extent. The objective of the present article is to investigate the thermomechanical, flame retardancy, and optical properties of the layered MMT/epoxy nanocomposites prepared by in situ polymerization method. This study has some original contributions to the literature that the relationship between the clay concentration-microstructureproperty (thermal, mechanical, flame, and optical properties) of the clay/epoxy nanocomposites prepared by two step method; mechanical stirring following by ultrasonication is given within the study.

\section{EXPERIMENTAL}

\section{Materials}

Nanocomposites were prepared using a modified Diglycidyl ether of bisphenol A (DGEBA)-epoxy resin (L135i, Enercon GmbH) and MMT (K10-Aldrich) with a cation exchange capacity of $120 \mathrm{meq} / 100 \mathrm{~g}$. An amine based curing agent (L135i/H137i, Enercon $\mathrm{GmbH}$ ) was blended to the epoxy resin as a hardener. For the modification of MMT, HTAC (Aldrich) with $25 \mathrm{wt} \%$ sol in water and hydrochloric acid were used.

\section{Modification of montmorillonite}

The modification of the clay surfaces were made based upon the method reported in the literature by several authors, Nigam et al. ${ }^{14}$ and Chen et al. ${ }^{15}$ Twenty grams of the clay (MMT) was dispersed into $400 \mathrm{~mL}$ distilled water and stirred at a temperature of $80^{\circ} \mathrm{C}$. About $0.05 \mathrm{~mol}$ of HTAC was mixed with $4.8 \mathrm{~mL} \mathrm{HCl}$ in $100 \mathrm{~mL}$ distilled water. This solution was poured into the hot clay-water mixture and stirred at a temperature of $80^{\circ} \mathrm{C}$ for $1 \mathrm{~h}$. The mixture was then filtered and washed with water until no chloride was detected. ${ }^{16}$ Chloride residue was determined using $\mathrm{AgNO}_{3}$ as described elsewhere. The organoclay (OMMT) was then obtained after drying the filtered material at $75^{\circ} \mathrm{C}$ for $2-3$ days in a vacuum oven.

\section{Synthesis of montmorillonite-epoxy nanocomposites}

The epoxy resin was blended with the desired amount $(1,3$, and $10 \mathrm{wt} \%)$ of OMMT and MMT at room temperature for $1 \mathrm{~h}$ using a mechanical stirrer. The blend was further hold in an ultrasonic bath for an additional $20 \mathrm{~min}$ to further disperse the clay in the resin. Then, a stochiometric amount (35 parts curing agent: 100 parts epoxy by weight) of the amine curing agent was added to the epoxy and the mixture was outgassed by vacuuming to remove bubbles. The blend was casted into silicon molds and the nanocomposites were cured at room temperature and post cured for $1 \mathrm{~h}$ at $80^{\circ} \mathrm{C}$ and $2 \mathrm{~h}$ at $150^{\circ} \mathrm{C}$.

\section{Characterization}

Glass transition temperature $\left(T_{g}\right)$ values were measured by differential scanning calorimetry (DSC) under nitrogen atmosphere at a flow rate of $50 \mathrm{~mL} /$ min. For this purpose, 5-6 mg of nanocomposites and neat epoxy samples were prepared within the aluminum crucibles. The $T_{g}$ value was determined by the midpoint method. The dynamic measurements were made at a constant heating rate of $10^{\circ} \mathrm{C}$ / min from 25 to $200^{\circ} \mathrm{C}$ to determine the effect of the clay addition on the $T_{g}$ of the epoxy. The thermomechanical properties of the epoxy and nanocomposite samples containing MMT and OMMT particles were investigated by means of Q800 dynamic mechanical analyzer (DMA) with a strain rate of 0.1 to investigate the storage modulus $\left(E^{\prime}\right)$, loss modulus $\left(E^{\prime \prime}\right)$, and $T_{g}$. For this purpose, dual cantilever clamp mode was used and a heating rate of $2^{\circ} \mathrm{C} / \mathrm{min}$ from 25 to $150^{\circ} \mathrm{C}$ was applied. DMA specimens were cut using a water-cooled diamond saw in the form of rectangular bars with the dimensions of $2.5 \mathrm{~mm}$ in thickness, $12 \mathrm{~mm}$ in width, and $55 \mathrm{~mm}$ in length.

Burning rate of the materials was measured using the UL-94 method according to the ASTM D 635. Specimens of $125 \pm 5 \mathrm{~mm}$ in length and $12.5 \pm 0.2$ $\mathrm{mm}$ in width were sectioned from each samples for this test. Optical transmission values of the samples were measured using HR2000 UV-NIR spectrometer from ocean optics. The effect of the clay content on the optical properties was investigated performing measurements on the samples with the thickness of $1,2,4$, and $6 \mathrm{~mm}$.

\section{RESULTS AND DISCUSSION}

The microstructure of the clay/epoxy nanocomposites prepared was characterized by XRD, scanning 


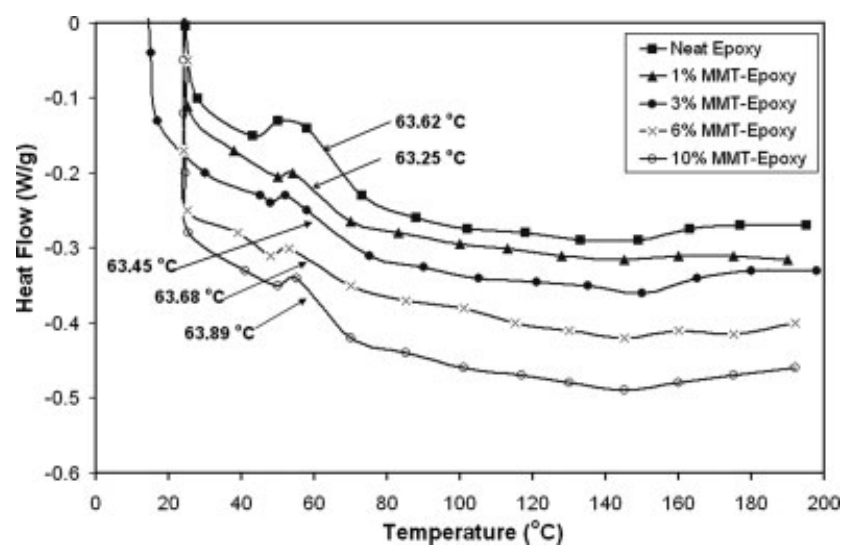

Figure 1 DSC thermograms for neat epoxy system and MMT/epoxy nanocomposites.

electron microscopy (SEM), and reported in our previous study. ${ }^{13}$ From XRD patterns, it was observed that MMT and OMMT exhibits characteristic XRD patterns corresponding to the d-spacing of $14.3 \AA$ at $2 \theta=6.17^{\circ}$ and $18.1 \AA$ at $2 \theta=4.87^{\circ}$, respectively, and the peaks correspond to the (001) plane reflections of clays. A greater d-spacing of OMMT implies intercalation of the clay galleries due to the application of surface modification. The increase of the d-spacing is due to the penetration of the surfactant molecules within the galleries and exchange of $\mathrm{Na}^{+}$ cations by the onium cation with a long alkyl chain of the surfactant during the surface modification process. XRD patterns of the nanocomposites made of MMT and OMMT clays with various loadings showed that the characteristic peaks of the clays are not detectable for the nanocomposites samples. This indicates the further intercalation of the clays within the polymer matrix. On the basis of SEM, at high clay concentrations (10 wt \%) clay agglomerations were visible within the epoxy matrix. Organoclays (OMMT) were better dispersed in the epoxy matrix as compared with those with MMT/epoxy nanocomposites. $^{13}$

Figures 1 and 2 show the DSC thermograms of neat epoxy and the nanocomposites prepared with MMT and OMMT, respectively. The $T_{g}$ value of neat epoxy was measured as $63.6^{\circ} \mathrm{C}$. This value remains almost constant with the addition of MMT. For OMMT/epoxy nanocomposites, up to $3 \mathrm{wt} \%$ addition of OMMT, $T_{g}$ increases to $68.9^{\circ} \mathrm{C}$. However, further addition of OMMT reduces the $T_{g}$. This observation implies that organically modified clays at relatively low contents better disperse in the polymer system and it restricts the motion of the epoxy network in the clay/epoxy system. At relatively higher concentrations, OMMT have effect that compensates the stiffening of the clay layers. This may be due to the plasticizing effect of high fraction of the surfactant used for surface modification especially at high clay contents. So, these two effects may have contribution on the chains to commence transition from the rigid glassy state to the soft rubbery state.

Several authors investigated the effects of clay incorporation within the epoxy matrix on the $T_{g}$ values. Chen et al. ${ }^{15}$ and Feng et al. ${ }^{17}$ similarly investigated the thermal behavior of nanocomposites and they found that the addition of MMT during the polymerization of the epoxy polymer decreased the $T_{g}$. On the other hand, higher $T_{g}$ value was obtained by incorporation of OMMT. Isik et al. ${ }^{18}$ also investigated the $T_{g}$ of the nanocomposites made of layered clay/epoxy and an increase of $T_{g}$ with respect to MMT loading was observed. This behavior was related to the mobility of the polymer chains hindered due to the interaction between the clay and polymer molecules resulting in higher $T_{g}$. In another work, a gradual decrease of $T_{g}$ by loading of clay was observed for the MMT/epoxy nanocomposites. ${ }^{14}$ Authors related this with (1) the polymer chains that are tied to the surface of the silicate by electrostatic interaction, thus reducing the surrounding entanglements, (2) modification of the epoxy network by its homopolymerization within the clay galleries, and (3) the excess of unreacted curing agent that may also plasticize the epoxy network.

The dynamic mechanical properties of the composites prepared were also studied by DMA. The dynamic storage modulus, loss modulus, and $\tan \delta$ versus temperature for neat epoxy are shown in Figures 3. Typical behavior of storage modulus of the neat epoxy and nanocomposites containing MMT and OMMT particles with various loading are given in Figures 4 and 5, respectively. Storage and loss modulus of the neat epoxy and clay/epoxy nanocomposites as a function of clay content are illustrated in Figures 6 and 7, respectively. On the graphs, storage modulus values are the data taken at room temperature and the loss modulus values are

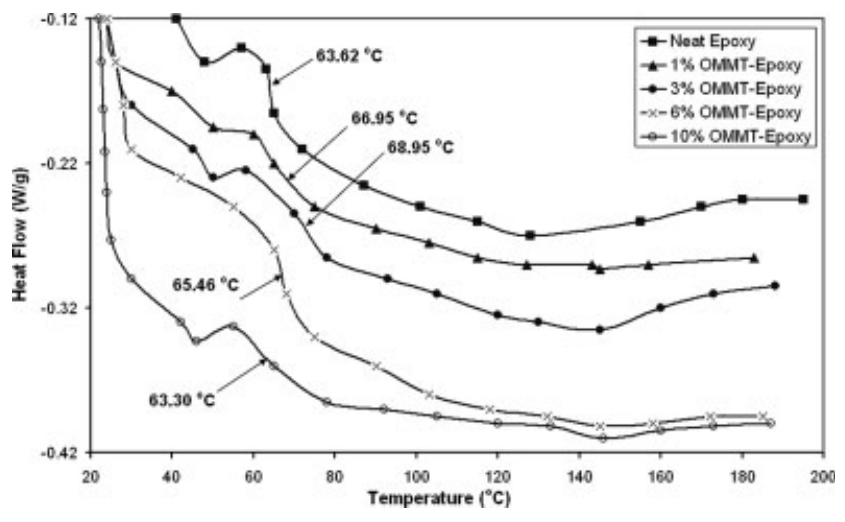

Figure 2 DSC thermograms for neat epoxy system and OMMT/epoxy nanocomposite. 


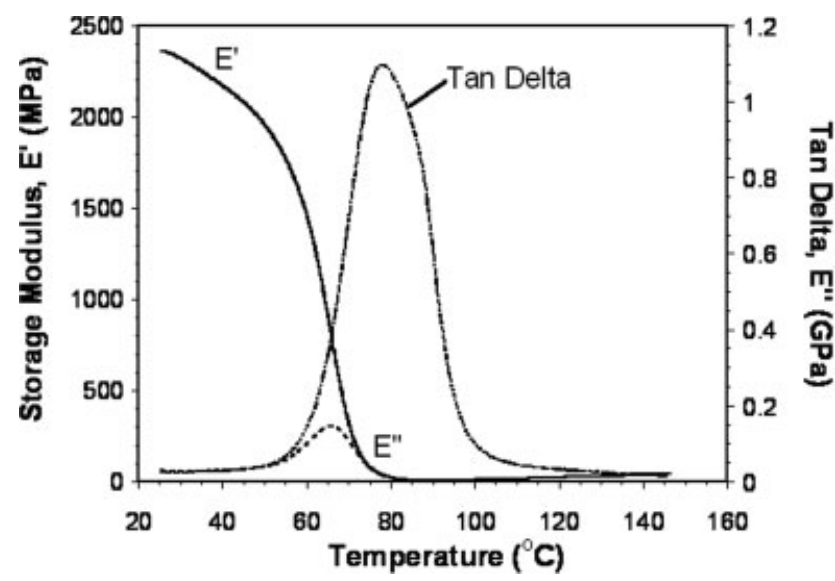

Figure 3 Typical DMA result for neat epoxy.

the maximum value at the peak of loss modulus curves.

The storage modulus of the nanocomposites containing MMT and OMMT particles are significantly higher than that of the neat epoxy as shown in Figure 6 . About 25 and $31 \%$ increase in storage modulus were achieved as a result of incorporation of 10 wt \% of MMT and OMMT clay layers into the epoxy matrix, respectively. The nanocomposites also show higher loss modulus values as compared with the neat epoxy as shown in Figure 7. The loss modulus of nanocomposites prepared with $10 \mathrm{wt} \%$ of MMT and OMMT are increased by about 36 and $43 \%$. Zhang et al. ${ }^{19}$ also examined the dynamic mechanical properties of composites prepared with diglycidyl ether of bisphenol A type epoxy resin and sodium clay. It was found that the storage modulus of the composite is $43 \%$ higher than those of neat epoxy (from 2.17 to $3.10 \mathrm{GPa}$ ), when the temperature is lower than the $T_{g}$. Similarly, Ranta et al. ${ }^{20}$ and Chen and Curliss ${ }^{21}$ reported a similar increase in storage modulus for the MMT/epoxy nanocomposite

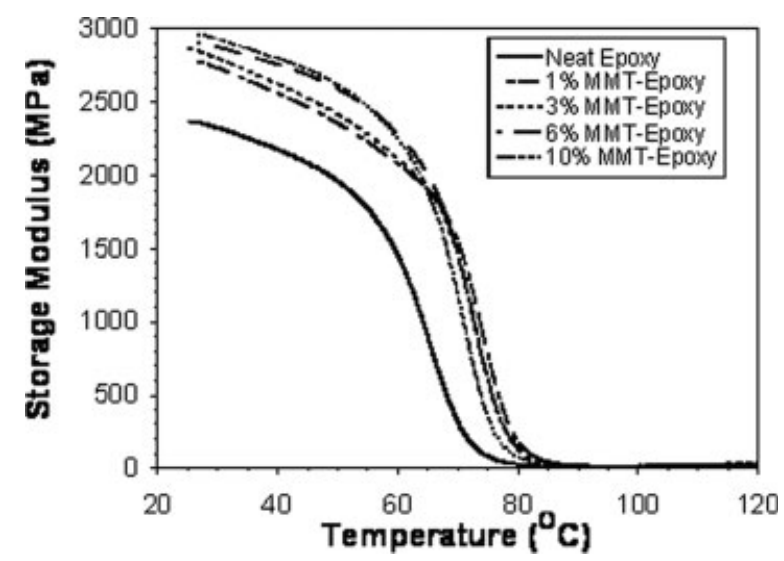

Figure 4 Storage modulus versus temperature of neat epoxy and MMT/epoxy nanocomposites at various clay loadings.

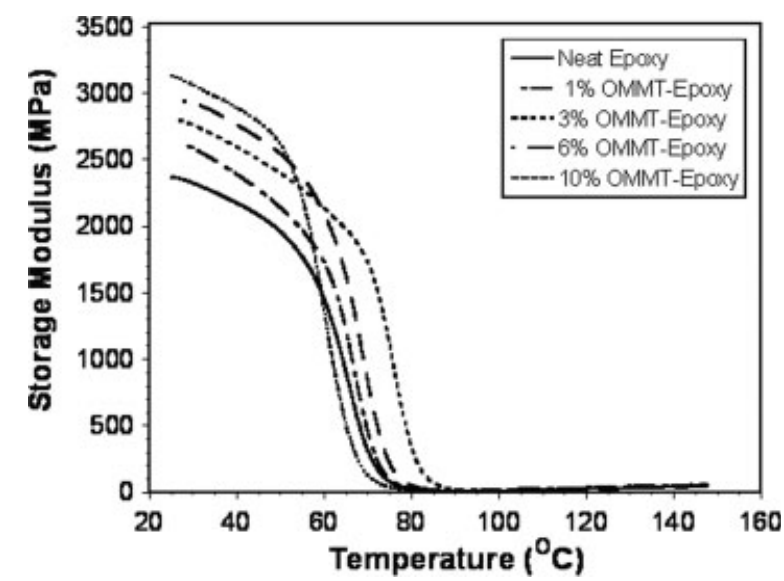

Figure 5 Storage modulus versus temperature of neat epoxy and OMMT/epoxy nanocomposites at various clay loadings.

system. This behavior was attributed to the high stiffness and high aspect ratio of the organoclay filler, which is frequently assumed to exceed above 1000. Also, Sarathi et al. ${ }^{22}$ investigated the thermal properties of epoxy nanocomposite materials and the DMA studies indicated that storage modulus of the material increased with the addition of nanoclay in epoxy resin. Yasmin et al. ${ }^{23}$ studied the clay/epoxy nanocomposites prepared by shear mixing. It was found that as the organoclay content is increased, the storage modulus is increased irrespective of clay type.

On the basis of the peak of the loss modulus, as shown in Figure 3, the $T_{g}$ of neat epoxy prepared in this study was determined as $57^{\circ} \mathrm{C}$. The $T_{g}$ values of the nanocomposites containing MMT and OMMT particles exhibited higher $T_{g}$ values than those for neat epoxy samples, as shown in Figure 8. The nanocomposites prepared with $3 \mathrm{wt} \%$ of OMMT showed

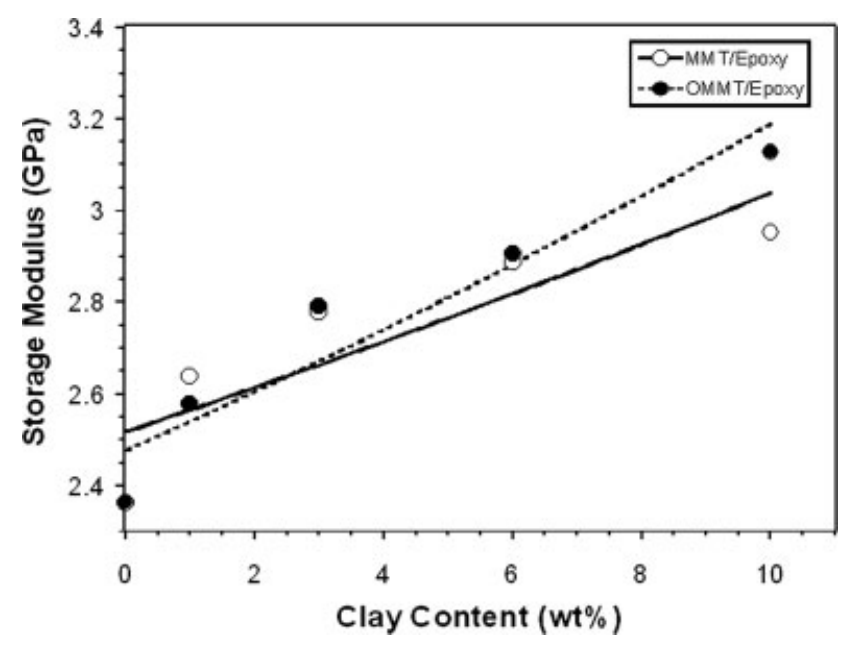

Figure 6 Storage modulus of the neat epoxy and clay/ epoxy nanocomposites as a function of clay content. 


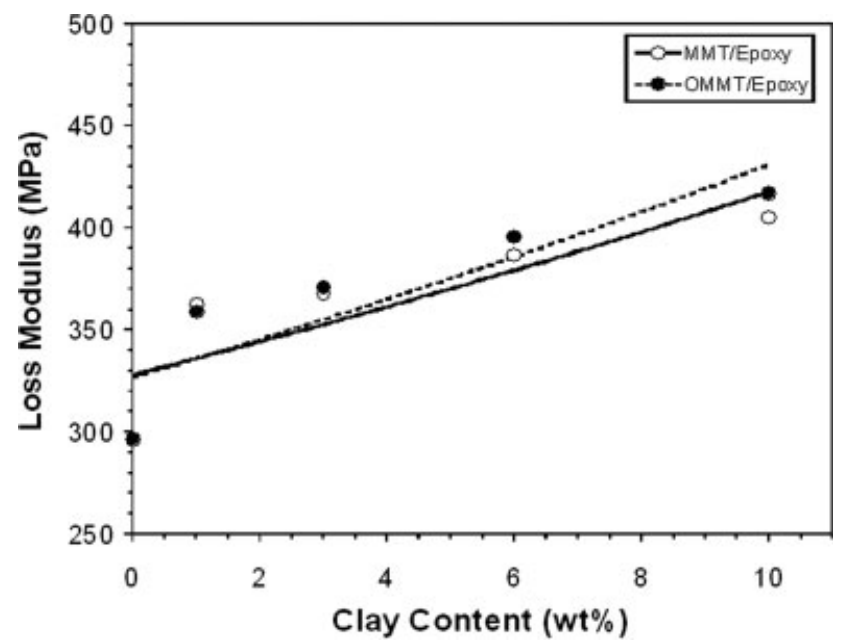

Figure 7 Loss modulus of the neat epoxy and clay/epoxy nanocomposites as a function of clay content.

the highest $T_{g}$ values. Incorporation of 3\% OMMT resulted by a $17^{\circ} \mathrm{C}$ increase in the $T_{g}$ of epoxy. However, it was observed that a further addition (above 3 wt \%) of OMMT and MMT into the nanocomposites decreased the $T_{g}$ values. This finding implies that clay layers at relatively low contents better disperse in the polymer system and it restricts the motion of the epoxy network in the clay/epoxy system. At relatively higher concentrations, the higher tendency of agglomeration and plasticizing effect of high fraction of the surfactant used for surface modification especially at high clay contents compensates the stiffening of the clay layers. So, these two effects may have contribution on the decrease of the $T_{g}$ of the nanocomposites at high concentrations. Yasmin et al. $^{23}$ found a continuous drop in $T_{g}$ with increasing clay content for organoclay/epoxy nanocomposites, observed by DMA. The author was concluded

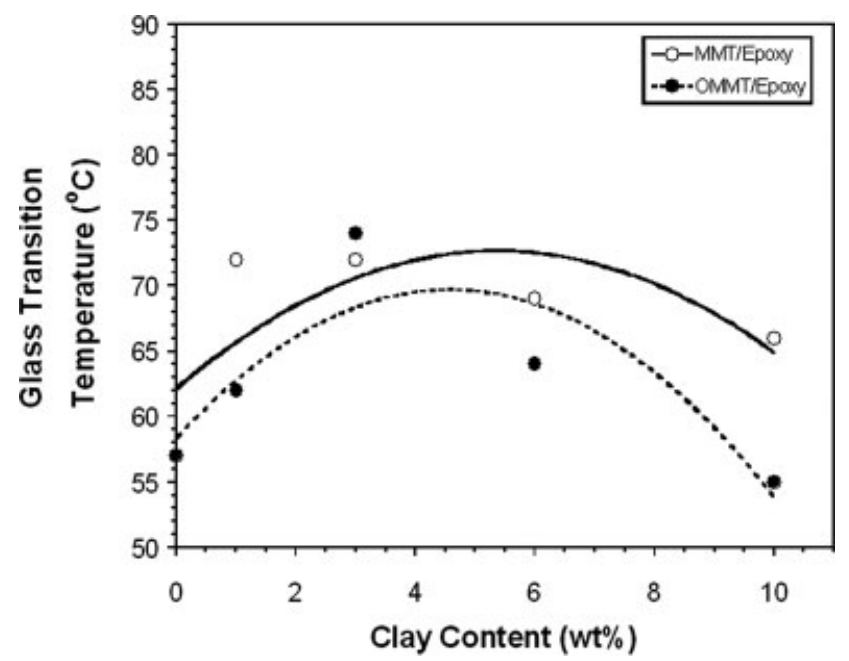

Figure $8 T_{g}$ of the neat epoxy and clay/epoxy nanocomposites as a function of clay content measured by DMA.

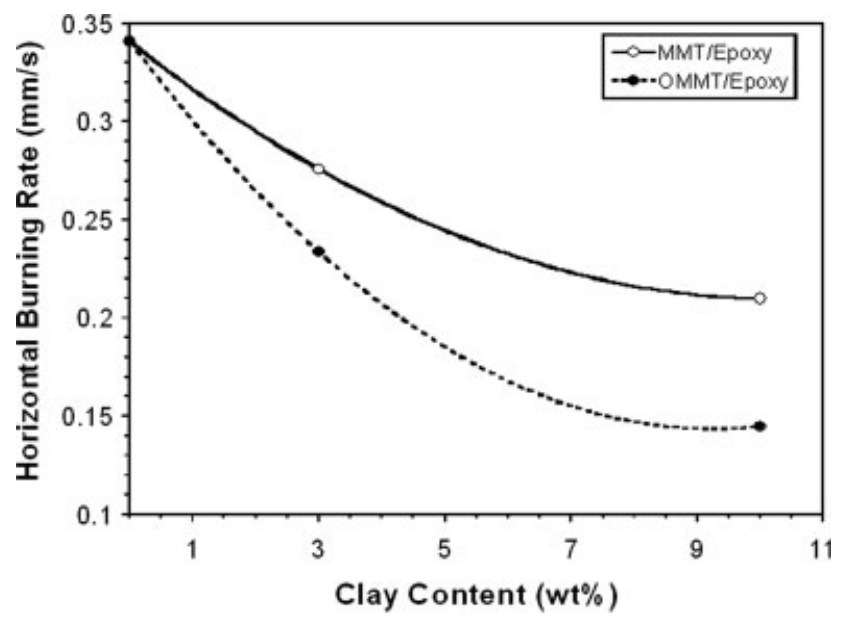

Figure 9 Horizontal burning rate of the neat epoxy and clay/epoxy nanocomposites.

that the drop in $T_{g}$ could be due to such as clay aggregates, interphase regions, adhesion problems at the clay- matrix interface at elevated temperatures, etc.

The UL-94 horizontal flammability test was used to determine the burning time, length and burning rate of MMT and OMMT incorporated epoxy nanocomposites, and the results are listed in Table I. The neat epoxy burns completely at atmospheric conditions, however, partial burning was observed for nanocomposite samples containing MMT and OMMT clay particles. Figure 9 shows the relative burning rate of the neat epoxy and nanocomposites as a function of clay loading. The burning rate for neat epoxy is $0.34 \mathrm{~mm} / \mathrm{s}$. Addition of MMT and OMMT clay particles into the epoxy matrix increases the flame retardancy of the epoxy. At $10 \mathrm{wt} \%$ clay loading, the burning rate decreases by 38 and $58 \%$ for MMT and OMMT nanocomposites, respectively. The barrier function of the clay layers reduces the transport of oxygen and waste-gasses and blocks the burning of polymer under the atmospheric conditions so that reduced flammability is observed for nanocomposites. The improvement on the flame resistivity of the composites is greater in the case of OMMT particle additions. As discussed in the previous study, ${ }^{13}$ OMMT particles showed better exfoliation within the polymer matrix as compared with those prepared with MMT. Better exfoliation of OMMT clay particles within the polymer matrix enhances the flammability resistance of epoxy as compared with MMT. The higher fraction of agglomerates within the MMT/epoxy composites acts more like in conventional filled ones, as addressed in the previous work. ${ }^{13}$ Camino et al. ${ }^{24}$ investigated flame retardant properties of the neat epoxy resin and the nanocomposites by cone calorimeter. The heat release rate (HRR) was recorded as a function of 


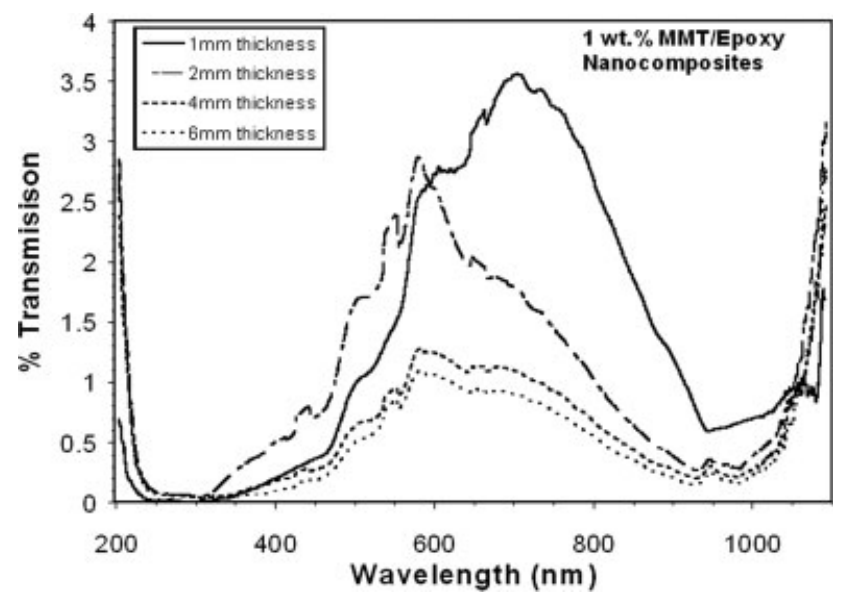

Figure 10 Light transmition rate for 1 wt \% MMT/epoxy nanocomposites at various thicknesses.

time. Cone calorimeter tests showed that the rate of heat release in the nanocomposite combustion was strongly reduced. The best fire retardant performance was observed by the nanocomposite containing 21 wt \% OMMT with 68\% HRR maximum decrease and burning time increased from 90 to $150 \mathrm{~s}$. Also, Ranta et al. ${ }^{25}$ reported the flammability properties of nanocomposites using rubber epoxy matrix. The flammability test was carried out using a flammability tester. The relative flammability was determined by adjusting the concentration of oxygen which permitted the specimen to burn. It was seen that LOI value gradually increased with an increase in the clay concentration. The author concluded that the decrease in flammability can be attributed to the increase in char yield.

Figures 10 and 11 are the typical examples showing the light transmission spectra in the 200-1100 $\mathrm{nm}$ wavelength range of nanocomposites with $1 \mathrm{wt}$ $\%$ MMT and OMMT for four different in thicknesses

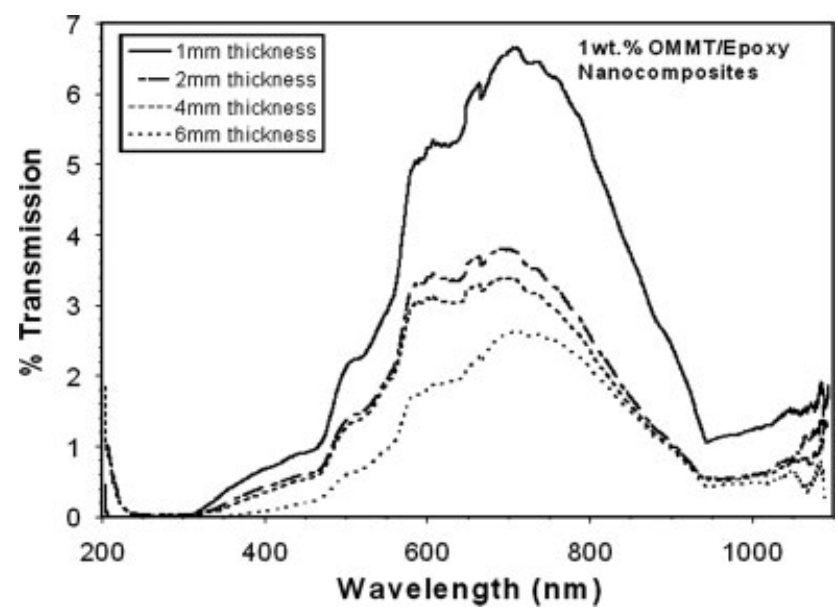

Figure 11 Light transmition rate for $1 \mathrm{wt} \%$ OMMT/ epoxy nanocomposites at various thicknesses.

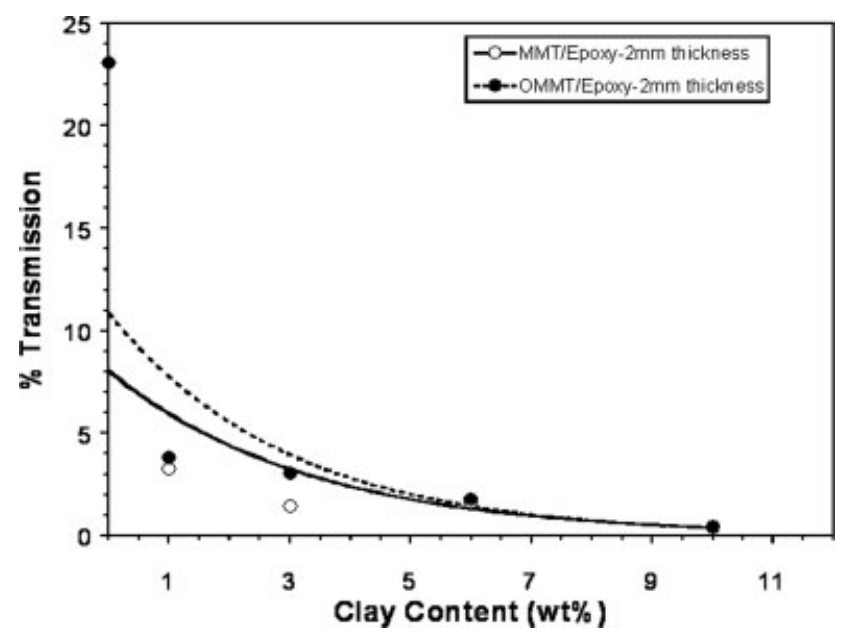

Figure 12 Percent transmitance of visible light at $700 \mathrm{~nm}$ as a function of clay content for the neat epoxy and clay/ epoxy nanocomposite samples at $2 \mathrm{~mm}$ thickness.

$(1,2,4$, and $6 \mathrm{~mm})$ of the samples. The transmission values decrease with increasing the specimen thickness, as expected. Surface modified OMMT clay particle additions to epoxy matrix exhibits better light transmission in comparison with MMT loading.

The transmission values at $700 \mathrm{~nm}$ wavelength for neat epoxy and nanocomposites made with MMT and OMMT clays at various loadings are shown in Figure 12. Light transmission of neat epoxy at 700 nm was measured to be about approximately $23 \%$. Optical transmission values are affected by MMT and OMMT clay incorporation into the epoxy. As the clay loading increases, transmission value decreases and the materials turned into opaque. Nanocomposites containing OMMT clay particles have slightly better transmission than those with MMT due to better exfoliation of the organically modified clay layers in the matrix. Clay layers with sizes less than the wavelength of visible light do not hinder light's passage. However, the clay layers have the dimensions in the micrometers the thickness in nanometer range. Therefore, the large surface of the clay plaques acts to scatter the light transmission and as the content of the plaques increases, the light passage is more hindered. Kagawa et al. ${ }^{26}$ revealed that the light transmittance of the glass particle-epoxy nanocomposites decreased with increase in glass particle volume fraction. Also, Optical properties of MMT/epoxy nanocomposites were studied by Deng et al. $^{27}$ and it was observed that with increasing OMMT loading, the light transmittances in the whole wavelength range systematically decreases. This result was concluded such that when the clay concentration increases, the particle surface per unit volume increases, and the light extinction obtained from the scattering at the interface of epoxy matrix and clay particles increase. 


\section{CONCLUSIONS}

Incorporation of the organically modified clay particles has a major effect on the properties of clay/ epoxy nanocomposites. DSC analysis revealed that incorporation of unmodified clays (MMT) with various content into the epoxy system does not affect the $T_{g}$ values, while the addition of $3 \%$ modified (OMMT) clay increases the $T_{g}$ by about $15^{\circ} \mathrm{C}$. Incorporation of clay leads to an increase in storage and loss modulus and an increase of the DMA measured $T_{g}$ of the nanocomposites. Optical transmission values are affected by clay incorporation. Nanocomposites containing OMMT clay particles exhibited better transparency than those with MMT. This is associated with a better exfoliation of clay layers from OMMT within the epoxy matrix. As the clay layers are dispersed well in the matrix, the nanometer level thickness of the layers does not act to scatter the light passage. Flammability test results showed that the flame retardancy of polymer increases by incorporation of clay particles. At $10 \%$ clay loading, the burning rate is decreased by 38 and $58 \%$ for MMT and OMMT nanocomposites, respectively.

\section{References}

1. Ahmadi, S. J.; Huang, Y. D.; Li, W. J Mater Sci 2004, 39, 1919.

2. Njuguna, J.; Pielichowski, K. Adv Eng Mater 2003, 5, 769.

3. Zanetti, M.; Lomakina, S.; Camino, G. Macromol Mater Eng $2000,279,1$.
4. Gao, F. Materials Today 2004, 50, 7.

5. Park, S.; Seo, D.; Lee, J. R. J Colloid Interf Sci 2002, 251, 160.

6. Chena, C.; Khobaib, M.; Curliss, D. Prog Org Coat 2003, 47, 376.

7. Kornmann, X.; Lindberg, H.; Berglund, L. A. Polymer 2001, 42, 1303.

8. Ray, S. S.; Okamoto, M. Prog Polym Sci 2003, 28, 1539.

9. Jordan, J.; Jacob, K. I.; Tannenbaum, R.; Shara, M. A.; Jasiuk, I. Mater Sci Eng A 2005, 393, 1.

10. Alexandre, M.; Dubois, P. Mater Sci Eng 2000, 28, 1.

11. Zilg, C.; Dietsce, F.; Hoffmann, B. Macromol Symp 2001, 169, 65.

12. Ma, J.; Xu, J.; Ren, J.; Yu, Z.; Mai, Y. Polymer 2003, 44, 4619.

13. Kaya, E.; Tanŏglu, M. Proceedings of Advancing with Composites Conference 2005, Italy. p 127.

14. Salahuddin, N. A. Polym Adv Technol 2004, 15, 251.

15. Chen, K. H.; Yang, S. M. J Appl Polym Sci 2002, 86, 414.

16. Feng, W.; Kadi, A.; Fudel, B. Polym Eng Sci 2002, 42, 1827.

17. Isik, I.; Yilmazer, U.; Bayram, G. Polymer 2003, 44, 6371.

18. Nigam, V.; Setua, D. K.; Mathur, G. N.; Kar, K. K. J Appl Polym Sci 2004, 93, 2201.

19. Zhang, K.; Wang, L.; Wang, F.; Wang, G.; Li, Z. J Appl Polym Sci 2004, 91, 2649.

20. Ranta, D.; Manoj, N. R.; Varley, R.; Raman, S.; Simon, G. P. Polym Int 2003, 52, 1403.

21. Curliss, D.; Chen, C. J Appl Polym Sci 2003, 90, 2276.

22. Sarathi, R.; Sahu, R. K.; Rajeshkumar, P. Mater Sci Eng A 2006, 445,567

23. Yasmin, A.; Luo, J. J.; Abot, J. L.; Daniel, I. M. Compos Sci Technol 2006, 66, 2415.

24. Camino, G.; Tartaglione, G.; Frache, A.; Manferti, C.; Costa, G. Polym Degrad Stab 2005, 90, 354.

25. Ratna, D.; Chakraborty, B. C.; Dutta, H.; Banthia, A. K. Poly Eng Sci 2006, 46, 1667.

26. Kagawa, Y.; Iba, H.; Tanaka, M.; Sato, H.; Chang, T. Acta Mater 1998, 46, 265.

27. Deng, Y.; Gu, A.; Fang, Z. Polym Int 2004, 53, 85. 